\title{
Risk factors for deep surgical site infection following thoracolumbar spinal surgery
}

\author{
${ }^{*}$ Hansen Deng, MD, ${ }^{1}$ Andrew K. Chan, MD, ${ }^{2}$ Simon G. Ammanuel, BS, ${ }^{2}$ Alvin Y. Chan, MD, ${ }^{3}$ \\ Taemin Oh, MD, ${ }^{2}$ Henry C. Skrehot, BS, ${ }^{2}$ Caleb S. Edwards, BA, ${ }^{2}$ Sravani Kondapavulur, BS, ${ }^{2}$ \\ Amy D. Nichols, RN, ${ }^{4}$ Catherine Liu, MD, ${ }^{5}$ John K. Yue, MD, ${ }^{2}$ Sanjay S. Dhall, MD, ${ }^{2}$ \\ Aaron J. Clark, MD, PhD, ${ }^{2}$ Dean Chou, MD, ${ }^{2}$ Christopher P. Ames, MD, ${ }^{2}$ and \\ Praveen V. Mummaneni, MD²
}

${ }^{1}$ Department of Neurological Surgery, University of Pittsburgh Medical Center, Pittsburgh, Pennsylvania; ${ }^{2}$ Department of Neurological Surgery, University of California, San Francisco, California; ${ }^{3}$ Department of Neurological Surgery, University of California, Irvine, California; ' ${ }^{2}$ epartment of Hospital Epidemiology and Infection Control, University of California, San Francisco, California; and ${ }^{5}$ Vaccine and Infectious Disease Division, Fred Hutchinson Cancer Research Institute and Division of Allergy and Infectious Diseases, University of Washington, Seattle, Washington

OBJECTIVE Surgical site infection (SSI) following spine surgery causes major morbidity and greatly impedes functional recovery. In the modern era of advanced operative techniques and improved perioperative care, SSI remains a problematic complication that may be reduced with institutional practices. The objectives of this study were to 1) characterize the SSI rate and microbial etiology following spine surgery for various thoracolumbar diseases, and 2) identify risk factors that were associated with SSI despite current perioperative management.

METHODS All patients treated with thoracic or lumbar spine operations on the neurosurgery service at the University of California, San Francisco from April 2012 to April 2016 were formally reviewed for SSI using the National Healthcare Safety Network (NHSN) guidelines. Preoperative risk variables included age, sex, BMI, smoking, diabetes mellitus (DM), coronary artery disease (CAD), ambulatory status, history of malignancy, use of preoperative chlorhexidine gluconate (CHG) showers, and the American Society of Anesthesiologists (ASA) classification. Operative variables included surgical pathology, resident involvement, spine level and surgical technique, instrumentation, antibiotic and steroid use, estimated blood loss (EBL), and operative time. Multivariable logistic regression was used to evaluate predictors for SSI. Odds ratios and $95 \%$ confidence intervals were reported.

RESULTS In total, 2252 consecutive patients underwent thoracolumbar spine surgery. The mean patient age was 58.6 \pm 13.8 years and $49.6 \%$ were male. The mean hospital length of stay was $6.6 \pm 7.4$ days. Sixty percent of patients had degenerative conditions, and $51.9 \%$ underwent fusions. Sixty percent of patients utilized presurgery $\mathrm{CHG}$ showers. The mean operative duration was $3.7 \pm 2$ hours, and the mean EBL was $467 \pm 829 \mathrm{ml}$. Compared to nonfusion patients, fusion patients were older (mean $60.1 \pm 12.7$ vs $57.1 \pm 14.7$ years, $p<0.001$ ), were more likely to have an ASA classification $>$ II $(48.0 \%$ vs $36.0 \%, p<0.001)$, and experienced longer operative times $(252.3 \pm 120.9$ minutes vs $191.1 \pm 110.2$ minutes, $p<0.001)$. Eleven patients had deep SSI $(0.49 \%)$, and the most common causative organisms were methicillinsensitive Staphylococcus aureus and methicillin-resistant $S$. aureus. Patients with $\operatorname{CAD}(p=0.003)$ or DM $(p=0.050)$, and those who were male $(p=0.006)$, were predictors of increased odds of SSI, and presurgery CHG showers $(p=$ 0.001 ) were associated with decreased odds of SSI.

CONCLUSIONS This institutional experience over a 4-year period revealed that the overall rate of SSI by the NHSN criteria was low at $0.49 \%$ following thoracolumbar surgery. This was attributable to the implementation of presurgery optimization, and intraoperative and postoperative measures to prevent SSI across the authors' institution. Despite pre-

\footnotetext{
ABBREVIATIONS ASA = American Society of Anesthesiologists; $\mathrm{CAD}=$ coronary artery disease $; \mathrm{CHG}=$ chlorhexidine gluconate; $\mathrm{Cl}=$ confidence interval; $\mathrm{DM}=$ diabetes mellitus; EBL = estimated blood loss; LOS = length of stay; MIS = minimally invasive surgery; MRSA = methicillin-resistant Staphylococcus aureus; MRSE = methicillinresistant Staphylococcus epidermidis; MSSA = methicillin-sensitive S. aureus; MSSE = methicillin-sensitive S. epidermidis; NHSN = National Healthcare Safety Network; $\mathrm{OR}=$ odds ratio; $\mathrm{SSI}=$ surgical site infection .
}

SUBMITTED April 22, 2019. ACCEPTED August 8, 2019.

INCLUDE WHEN CITING Published online November 1, 2019; DOI: 10.3171/2019.8.SPINE19479.

${ }^{*}$ H.D. and A.K.C. contributed equally to this work. 
vention measures, having a history of CAD or DM, and being male, were risk factors associated with increased SSI, and presurgery $\mathrm{CHG}$ shower utilization decreased SSI risk in patients.

https://thejns.org/doi/abs/10.3171/2019.8.SPINE19479

KEYWORDS surgical site infection; thoracolumbar surgery; spinal surgery; nonfusion surgery; fusion surgery

$\mathrm{S}$ URGICAL site infection (SSI) is a problematic complication following spine surgery, with reported rates ranging from $0.7 \%$ to $10 \% .^{10,23,24,27,28,31}$ The diagnosis and treatment of SSI can be difficult, and it frequently necessitates reoperation for wound debridement and/or instrumentation removal, prolonged hospitalization, and an extended antibiotic course. For these reasons, SSI remains a notable cause of postoperative morbidity, mortality, and high acuity of medical care, with treatment costs that range from $\$ 15,800$ to $\$ 43,900 .^{5,9,21,35}$

In the context of an aging population and an increase in the number of spinal procedures performed, ${ }^{19,38}$ the need to improve our understanding and prevention of SSI remains important. The current standards of practice support the use of prophylactic antibiotics to decrease SSI after spinal surgery. ${ }^{20,37}$ Indeed, there is level II and III evidence on the efficacy of a single preoperative dose of antibiotics followed by intraoperative redosing as needed. ${ }^{29}$ The consensus over the source of SSI is that native skin microflora cause the majority of SSIs after spine procedures. Despite advanced antiseptic protocols, including the use of presurgery antiseptic showers and antibiotics ${ }^{13-17}$ current practices have failed to eliminate SSI, and the reported rates vary from one institution to another.

Several risk factors have been studied in spine surgery patients that can possibly predispose patients to SSI after spine operations, including diabetes mellitus (DM), smoking, obesity, and prolonged operative time. ${ }^{7,23,29}$ For a number of reasons, including variations in neurosurgical practices and the lack of database granularity, the capacity to identify risk factors that increase SSI has been limited. To address this gap in knowledge, we systematically evaluated all patients who underwent thoracic or lumbar spine operations from 2012 to 2016 and identified candidate risk factors that were independently associated with SSI. We hypothesize that demographics, comorbidities (including but not limited to DM), and operative variables may be associated with risk of SSI, and that utilization of presurgical chlorhexidine gluconate $(\mathrm{CHG})$ showers by patients may be associated with reduced risks of SSI.

\section{Methods \\ Study Design and Data Collection}

The study received IRB review and approval from the University of California, San Francisco. The study contained fully de-identified patient information, and therefore patient consent was not required. A total of 4266 spine surgeries were performed during a period between April 2012 and April 2016 that met the NHSN criteria on SSI follow-up after a spine operation, as described below. All spine procedures were performed at a single, high-volume, academic facility by a neurosurgical team, as previously described. ${ }^{6}$ The prevention strategies of SSI implemented in our spine surgery patients are illustrated in Fig. 1. A presurgical CHG shower protocol was implemented in November 2013 for all patients treated at our institution. Patients were instructed to shower with CHG liquid soap daily for a minimum of three times, including two times the nights prior to surgery and once the morning of admission for surgery (Fig. 2).

All patients who underwent thoracic and/or lumbar surgery with SSI surveillance were included in the study. Patients with cervical and cervicothoracic surgery, and surgeries extending beyond the thoracolumbar region, were not included in this study. Per our institutional protocol, all patients regardless of sex received standard pre-incision clipping of their hair as part of standard sterilization. We

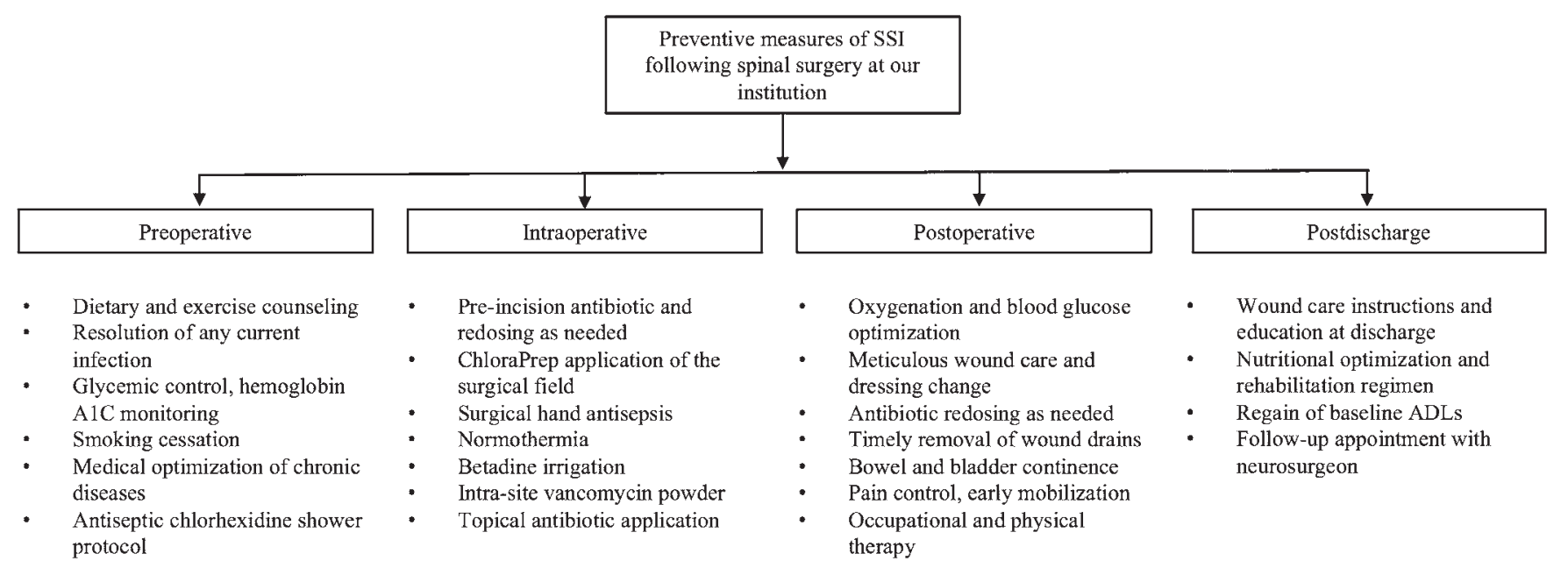

FIG. 1. Flowchart depicting the perioperative and intraoperative preventive measures of SSI for patients undergoing spinal surgery at our institution. $A D L=$ activities of daily living. 


\section{UC HEALTH}

Preparing for your surgery

Shower with Chlorhexidine (CHG) soap to prevent infection

Instructions:

You should shower with CHG soap a minimum of three times before your surgery, or more often as directed by your surgeon. In the event that your surgery date is moved to an earlier date, complete as many showers as you can manage. Emergency cases are excluded from these bathing instructions.

Showering several times before surgery blocks germ growth and provides the best protection when used at least 3 times in a row.

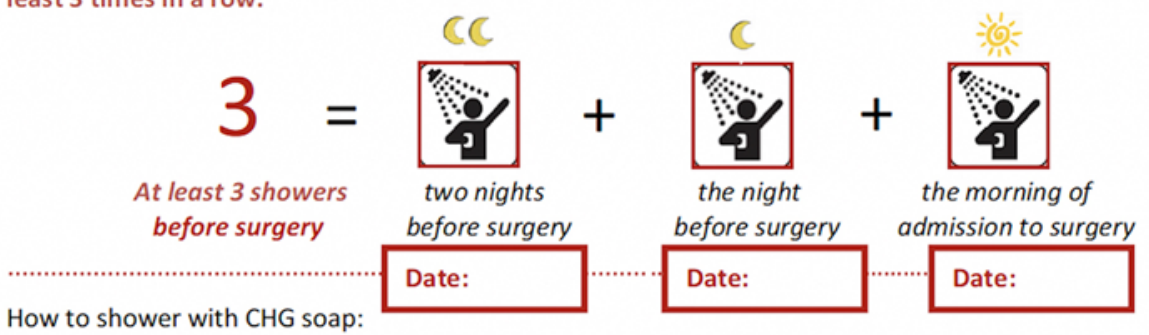

1. Rinse your body with warm water.

2. Wash your hair with regular shampoo. Rinse your hair with water. If you are having neck surgery, use CHG soap instead of your regular shampoo to wash your hair. Rinse your hair with water.

3. Wet a clean sponge. Turn off the water. Apply CHG liberally.

4. Firmly massage all areas: neck, arms, chest, back, abdomen, hips, groin, genitals (external only) and buttocks. Clean your legs and feet and between your fingers and toes. Pay special attention to the site of your surgery and all surrounding skin. Ask for help to clean your back if you have a spinal surgery.

\section{! Caution: When using CHG soap, avoid contact with eyes, nose, ear canals and mouth.}

Important reminders:

- Do not use any other soaps or body wash when using CHG. Other soaps can block the CHG benefits.

- After showering, do not apply lotion, cream, powder, deodorant, or hair conditioner.

- Do not shave or remove body hair. Facial shaving is permitted. If you are having head surgery, ask your doctor whether you can shave.

- $\quad$ CHG is safe to use on minor wounds, rashes, burns, and over staples and stitches.

- Allergic reactions are rare but may occur. If you have an allergic reaction, stop using CHG and call your doctor if you have a skin irritation.

- If you are allergic to CHG, please follow the bathing instructions above using an over-the-counter regular soap instead of $\mathrm{CHG}$

UCDAVIS UCIrvine Health UCLA Health UCSan Diego vo USF Medical Center

FIG. 2. Instructional handout given to patients at the preoperative appointment to demonstrate the CHG wash protocol. Image credit: 2013-2016 University of California, Office of the President (PI: Torriani). Developing standardized operative bundles to decrease surgical site infections (SSI). All rights reserved. Copyright UC Health. Published with permission. Figure is available in color online only.

have included this in the Methods section. Demographics (age, sex), comorbidities (BMI, DM, coronary artery disease [CAD], baseline malignancy, smoking status, ambulation status, use of preoperative CHG showers, American Society of Anesthesiologists [ASA] classification), surgical pathology (degenerative, deformity, tumor, trauma, or other), spinal surgical level, intraoperative variables (revision, fusion, resident involvement, open versus minimally invasive surgery [MIS], operative approach, estimated blood loss [EBL], operative duration), antibiotic and steroid use, 
and hospital length of stay (LOS) were documented for each patient. The data reporting adhered to Strengthening the Reporting of Observational Studies in Epidemiology (STROBE) recommendations. ${ }^{33}$

\section{Infection Classification and Outcome Monitoring}

The rate and total number of SSIs per quarter were identified in accordance with the National Healthcare Safety Network (NHSN) SSI event identification guidelines, and consistent with our prior publication. ${ }^{6}$ In this study, NHSN operative procedure categories included all spinal fusions, laminectomies, and refusions of the spine. Our institution's Department of Hospital Epidemiology and Infection Control reviewed records for patients undergoing spine surgery, as identified by ICD-9 procedure codes (Supplemental Table 1). Additionally, case records were independently reviewed to identify additional cases of SSI. Patient records associated with the following were identified through an electronic surveillance system: 1) positive culture of tissue, body fluid, wound, or blood; 2) return to surgery for incision and debridement; or 3) ICD9 diagnosis codes suggestive of SSI (996.6, 996.69, 998.51, and 998.59). Records meeting any of the above criteria were then reviewed in detail by a hospital infection preventionist who was not associated with the current study. SSIs were classified as either superficial or deep. Criteria for superficial SSIs were defined as infections occurring within 30 days of surgery and involving only skin and subcutaneous tissue, while criteria for deep SSIs were infections that occurred within 30 days of surgery and involved deeper layers (e.g., fascial and subfascial muscle layers). SSIs from fusion procedures were defined as occurring within 90 days of surgery.

\section{Statistical Analysis}

Categorical variables were presented as proportions, and continuous variables using means and standard deviations. Univariate analyses used Pearson's chi-square test. The Fisher exact test was used for analyses with cell counts $<5$. Variables with $\mathrm{p}$ values $<0.20$ were incorporated into the multivariable model. The outcome variable was SSI, and multivariable analysis of SSI was performed using binary logistic regression. Odds ratios (ORs) and their associated 95\% confidence intervals (CIs) were reported. Significance was assessed at $p \leq 0.05$. Statistical analyses were executed using the Statistical Package for Social Sciences (version 25, IBM Corp.).

\section{Results}

\section{Demographics, Comorbidities, and Operative Variables}

In total, 4266 patients were treated with spinal procedures between April 2012 and April 2016. Of these, 2252 patients had thoracic or lumbar surgeries and were included for subsequent analyses. Summary data of demographic, comorbidity, and operative variables for all patients are listed in Table 1 . The mean patient age was 58.6 \pm 13.8 years, $49.6 \%$ of patients were male, and the mean BMI was $28.6 \pm 6.3 \mathrm{~kg} / \mathrm{m}^{2}$. The comorbidities included DM (7.9\%), CAD (6.1\%), history of malignancy (9.6\%), smoking (10.8\%), and impaired ambulation (19.4\%). Sixty percent of patients utilized a presurgical $\mathrm{CHG}$ shower protocol, and $42.2 \%$ of patients were classified as ASA class $>2$. Primary spinal pathologies were degenerative conditions $(61.9 \%)$, tumor $(16.8 \%)$, deformity $(13.5 \%)$, trauma $(2.0 \%)$, and other $(5.8 \%)$.

According to the spinal level of procedure, $79.4 \%$ of operations were $\leq \mathrm{L} 2-\mathrm{S} 1$ (Table 1). The rate of resident involvement in the surgeries was $77.8 \%$. Twenty-two percent of operations were MISs, and $12.6 \%$ of surgeries were revisions. By operative approach, $75.9 \%$ were posterior, $14.4 \%$ anterior, $3.5 \%$ lateral, and $6.3 \%$ 2-stage surgeries. The rate of intraoperative antibiotic use was $95.7 \%$ and postoperative antibiotic use was $66.3 \%$. Perioperative steroid use during the pre- or postoperative period was $43.7 \%$. The mean operative duration was $3.7 \pm 2$ hours, and the mean EBL was $467 \pm 829 \mathrm{ml}$.

\section{Risk Factors of SSIS}

The results of the univariate analysis for the risk factors associated with SSI are provided in Table 1. In total, 11 patients $(0.49 \%)$ experienced postoperative SSIs. The SSI rates for men and women were $0.9 \%$ and $0.1 \%$, respectively, using the chi-square test $(\mathrm{p}=0.006)$. Patients with $\mathrm{DM}(1.7 \%$ vs $0.4 \%, \mathrm{p}=0.050)$ and CAD $(2.9 \%$ vs $0.3 \%, \mathrm{p}$ $=0.003)$ also had higher rates of SSI. Patients using preoperative CHG showers had lower rates of SSI $(1.1 \%$ vs $0.1 \%, \mathrm{p}=0.001)$. Also in the univariate analysis, patients receiving postoperative antibiotics were associated with lower rates of SSI $(0.3 \%$ vs $0.8 \%, p=0.143)$, and EBL $\geq 1 \mathrm{~L}$ with a higher SSI rate $(1.0 \%$ vs $0.4 \%, \mathrm{p}=0.196)$. Table 2 shows the characteristics of the patient cases with SSI and the cultured microorganisms. All of the identified infections constituted deep SSIs involving the fascial and subfascial tissues as defined by the NHSN guidelines. Of the 11 patients with SSIs, all required reoperation for wound debridement, tissue culture, and wound washout. Four of these patients also needed hardware removal and revision operation. The pathogens were methicillin-sensitive Staphylococcus aureus (MSSA; $\mathrm{n}=2$ ), methicillinresistant $S$. aureus (MRSA; $\mathrm{n}=2$ ), vancomycin-resistant Enterococcus faecium $(\mathrm{n}=2)$, Propionibacterium acnes ( $\mathrm{n}=2$ ), methicillin-sensitive Staphylococcus epidermidis (MSSE; $\mathrm{n}=1$ ), methicillin-resistant $S$. epidermidis (MRSE) $(\mathrm{n}=1)$, and unknown $(\mathrm{n}=1)$. Subgroup analysis of patients pre- and post-CHG protocol implementation in November 2013 demonstrated that SSI was lower postimplementation (OR $0.09,95 \%$ CI 0.11-0.70) while controlling for other patient variables in the multivariate analysis.

After adjusting for all variables with $\mathrm{p}$ values $<0.20$ in the univariate analysis (sex, DM, CAD, presurgical CHG shower, ASA classification, surgical approach, EBL, and postoperative antibiotic), on multivariable analysis (Supplemental Table 2) male sex had an OR of 11.75 (95\% CI $1.45-96.46, p=0.021)$ for SSI compared to female sex (Fig. 3A), and patients with CAD had an OR of 8.78 (95\% CI $1.99-38.72, p=0.004$ ) for SSI compared to patients without CAD (Fig. 3B). In addition, patients with presurgical CHG showers had an OR of 0.08 (95\% CI 0.01-0.67, p $=0.019$ ) for SSI compared to patients without CHG showers (Fig. 3C). DM did not reach statistical significance for predicting SSI on multivariable regression. 
TABLE 1. Characteristics of all patient cohorts following thoracic or lumbar operations, and univariate analysis of patients with and without SSI

\begin{tabular}{|c|c|c|c|c|}
\hline Parameter & All (\%) & No SSI (\%) & SSI (\%) & p Value \\
\hline No. of patients & 2252 & 2241 & 11 & \\
\hline Mean age $\pm S D$, yrs & $58.6 \pm 13.8$ & $58.6 \pm 13.7$ & $61.1 \pm 15.3$ & 0.553 \\
\hline Males & $1118(49.6)$ & $1108(49.4)$ & $10(90.9)$ & 0.006 \\
\hline Mean BMI $\pm \mathrm{SD}, \mathrm{kg} / \mathrm{m}^{2}$ & $28.6 \pm 6.3$ & $28.6 \pm 6.3$ & $29.1 \pm 7.1$ & 0.801 \\
\hline DM & $178(7.9)$ & $175(7.8)$ & $3(27.3)$ & 0.050 \\
\hline CAD & $138(6.1)$ & $134(6.0)$ & $4(36.4)$ & 0.003 \\
\hline History of malignancy & $215(9.5)$ & $214(9.5)$ & $1(9.1)$ & 0.996 \\
\hline Smoker & $242(10.8)$ & $241(10.8)$ & $1(9.1)$ & 0.858 \\
\hline Ambulation & $1837(81.6)$ & $1828(81.6)$ & $11(100)$ & 0.983 \\
\hline ASA classification & & & & 0.132 \\
\hline$\leq \|$ & $1301(57.8)$ & $1292(57.7)$ & $9(81.8)$ & \\
\hline$>$ II & $951(42.2)$ & $949(42.3)$ & $2(18.2)$ & \\
\hline Presurgical CHG shower & $1347(59.8)$ & $1346(60.1)$ & $1(9.1)$ & 0.001 \\
\hline Surgical pathology & & & & 0.637 \\
\hline Degenerative & $1394(61.9)$ & $1388(61.9)$ & $6(54.5)$ & \\
\hline Deformity & $303(13.5)$ & $300(13.4)$ & $3(27.3)$ & \\
\hline Tumor & $379(16.8)$ & $377(16.8)$ & $2(18.2)$ & \\
\hline Trauma & $46(2.0)$ & $46(2.1)$ & $0(0)$ & \\
\hline Other & $130(5.8)$ & $130(5.8)$ & $0(0)$ & \\
\hline Resident involvement & $1753(77.8)$ & $1744(77.8)$ & $9(81.8)$ & 0.750 \\
\hline Open vs MIS surgery & & & & 0.267 \\
\hline Open & $1763(78.3)$ & $1757(78.4)$ & $7(63.6)$ & \\
\hline MIS & $489(21.7)$ & $484(21.6)$ & $4(36.4)$ & \\
\hline Revision & $283(12.6)$ & $282(12.6)$ & $1(9.1)$ & 0.727 \\
\hline Fusion & $1168(51.9)$ & $1162(51.9)$ & $7(63.6)$ & 0.551 \\
\hline Surgical level & & & & 0.413 \\
\hline$\leq 5$-level thoracic/thoracolumbar & $236(10.5)$ & $236(10.5)$ & $0(0)$ & \\
\hline$\leq \mathrm{L} 2-\mathrm{S} 1$ & $1789(79.4)$ & $1779(79.4)$ & $9(81.8)$ & \\
\hline$>$ L2-S1 \& < T10-pelvis & $179(7.9)$ & $177(7.9)$ & $2(18.2)$ & \\
\hline$\geq$ T10-pelvis & $48(2.1)$ & $49(2.2)$ & $0(0)$ & \\
\hline Surgical approach & & & & 0.011 \\
\hline Posterior & $1709(75.9)$ & $1701(75.9)$ & $7(63.6)$ & \\
\hline Anterior & $324(14.4)$ & $324(14.5)$ & $0(0)$ & \\
\hline Lateral & $78(3.5)$ & $76(3.4)$ & $2(18.2)$ & \\
\hline 2-stage & $141(6.3)$ & $140(6.2)$ & $2(18.2)$ & \\
\hline Intraop antibiotics & $2156(95.7)$ & $2145(95.7)$ & $11(100)$ & - \\
\hline Postop antibiotics & $1493(66.3)$ & $1488(66.4)$ & $5(45.5)$ & 0.143 \\
\hline Pre/postop steroids & $984(43.7)$ & $980(43.7)$ & $4(36.4)$ & 0.765 \\
\hline EBL, L & & & & 0.196 \\
\hline$<1$ & $1855(85.9)$ & $1846(85.9)$ & $8(72.7)$ & \\
\hline$\geq 1$ & $305(14.1)$ & $303(14.1)$ & $3(27.3)$ & \\
\hline Op duration, hrs & & & & 0.263 \\
\hline$<2$ & $421(18.7)$ & 417 (18.6) & $3(27.3)$ & \\
\hline $2-5$ & $1352(60.1)$ & $1349(60.2)$ & $4(36.4)$ & \\
\hline$>5$ & $478(21.2)$ & $474(21.2)$ & $4(36.4)$ & \\
\hline Mean LOS \pm SD, days & $6.6 \pm 7.4$ & $6.6 \pm 7.4$ & $6.1 \pm 2.7$ & 0.806 \\
\hline
\end{tabular}

Boldface type indicates statistical significance. 
TABLE 2. Summary data of patients with SSIs following thoracic or lumbar spinal surgery

\begin{tabular}{|c|c|c|c|c|c|c|c|c|c|c|c|c|}
\hline $\begin{array}{l}\text { Age (yrs), } \\
\text { Sex }\end{array}$ & $\mathrm{DM}$ & CAD & $\begin{array}{l}\text { ASA } \\
\text { Class }\end{array}$ & $\begin{array}{c}\text { CHG } \\
\text { Shower }\end{array}$ & Pathology & Level & Fusion & Approach & $\begin{array}{c}\text { EBL } \\
(\mathrm{L})\end{array}$ & Transfusion & $\begin{array}{l}\text { Op Time } \\
\text { (hrs) }\end{array}$ & Culture \\
\hline $76, \mathrm{M}$ & Yes & Yes & $\|$ & No & Degenerative & $\leq \mathrm{L} 2-\mathrm{S} 1$ & Yes & 2-stage & $>1$ & 2 units $p R B C$ & $>5$ & MSSE \\
\hline $80, M$ & No & Yes & II & No & Deformity & $\leq \mathrm{L} 2-\mathrm{S} 1$ & No & Posterior & $<1$ & No & $<2$ & MRSE \\
\hline $52, F$ & No & No & II & No & Tumor & $\leq \mathrm{L} 2-\mathrm{S} 1$ & Yes & Lateral & $<1$ & No & $>5$ & $\begin{array}{l}\text { Vancomycin-resistant } \\
\text { E. faecium }\end{array}$ \\
\hline $72, \mathrm{M}$ & No & Yes & II & No & Deformity & $\begin{array}{l}>\text { L2-S1, < } \\
\text { T10-pelvis }\end{array}$ & Yes & 2-stage & $>1$ & 2 units $p R B C$ & $>5$ & MSSA \\
\hline $34, \mathrm{M}$ & No & No & II & No & Degenerative & $\leq \mathrm{L} 2-\mathrm{S} 1$ & Yes & Lateral & $<1$ & No & $2-5$ & Unknown* \\
\hline $51, M$ & Yes & No & III & No & Degenerative & $\leq \mathrm{L} 2-\mathrm{S} 1$ & No & Posterior & $<1$ & No & $<2$ & $\begin{array}{l}\text { Vancomycin-resistant } \\
\text { E. faecium }\end{array}$ \\
\hline $52, \mathrm{M}$ & No & No & I & No & Degenerative & $\leq \mathrm{L} 2-\mathrm{S} 1$ & No & Posterior & $<1$ & No & $2-5$ & $P$. acnes \\
\hline $73, M$ & No & No & $\|$ & No & Degenerative & $\leq \mathrm{L} 2-\mathrm{S} 1$ & No & Posterior & $<1$ & No & $<2$ & MSSA \\
\hline $73, M$ & No & No & III & No & Tumor & $\begin{array}{l}>\text { L2-S1, < } \\
\text { T10-pelvis }\end{array}$ & Yes & 2-stage & $<1$ & No & $2-5$ & MRSA \\
\hline $43, M$ & No & No & II & Yes & Degenerative & $\leq \mathrm{L} 2-\mathrm{S} 1$ & Yes & Posterior & $>1$ & 2 units $p R B C$ & $>5$ & MRSA \\
\hline $66, M$ & Yes & Yes & II & No & Deformity & $\leq \mathrm{L} 2-\mathrm{S} 1$ & Yes & Posterior & $<1$ & No & $<2$ & P. acnes \\
\hline
\end{tabular}

pRBC = packed red blood cells.

* Patient received antibiotics preoperatively; therefore, intraoperative cultures were negative. However, pathology demonstrated microabscesses.

\section{Subgroup Analysis of Patients With Nonfusion and Fusion Surgery}

In total, 1168 patients underwent spinal fusion surgery, of which there were 7 SSIs $(0.6 \%)$ (Table 3 ). A total of 1084 patients had nonfusion surgery, and there were 4 SSIs $(0.4 \%)$. There was no statistical difference in the rate of SSI between these two cohorts (Fig. 4A) as well as according to the region of spine surgery (Fig. 4B). However, we observed that patients undergoing fusion were significantly older (mean $60.1 \pm 12.7$ vs $57.1 \pm 14.7$ years, $p<0.001$ ), had a higher proportion of men $(52.7 \%$ vs $46.3 \%$, $\mathrm{p}=0.002)$, and were more likely to have an ASA classification $>$ II $(48.0 \%$ vs $36.0 \%$, p < 0.001). Fusion patients were significantly more likely to undergo open spinal surgery $(80.2 \%$ vs $76.2 \%, p=0.021$ ) as opposed to MIS, and had longer operative durations (mean $252.3 \pm 120.9$ vs $191.1 \pm 110.2$ minutes, $\mathrm{p}<0.001)$.

\section{Discussion}

SSI after spinal surgery is a major complication that results in increased patient morbidity, mortality, and healthcare burden. ${ }^{5,9,18,35}$ Prior studies have demonstrated SSI rates ranging widely from $0.7 \%$ to $10.0 \%$, depending on the patient population, pathology, and type of procedure. $1,10,23,24,27,28,31,36$ Unfortunately, large administrative registries lack the granularity to account for a number of perioperative and intraoperative variables that can affect the infection rate among institutions. In addition to patient characteristics and operative variables playing a role, the location of spine surgery also affects the rate of SSI, with thoracic $(2.1 \%)$ and lumbar (1.6\%) procedures more prone to SSI than cervical surgery $(0.8 \%) .{ }^{30}$ The present study captures these variables and further clarifies their effect on SSI following spine surgery.

To date, only a handful of studies have analyzed an en-
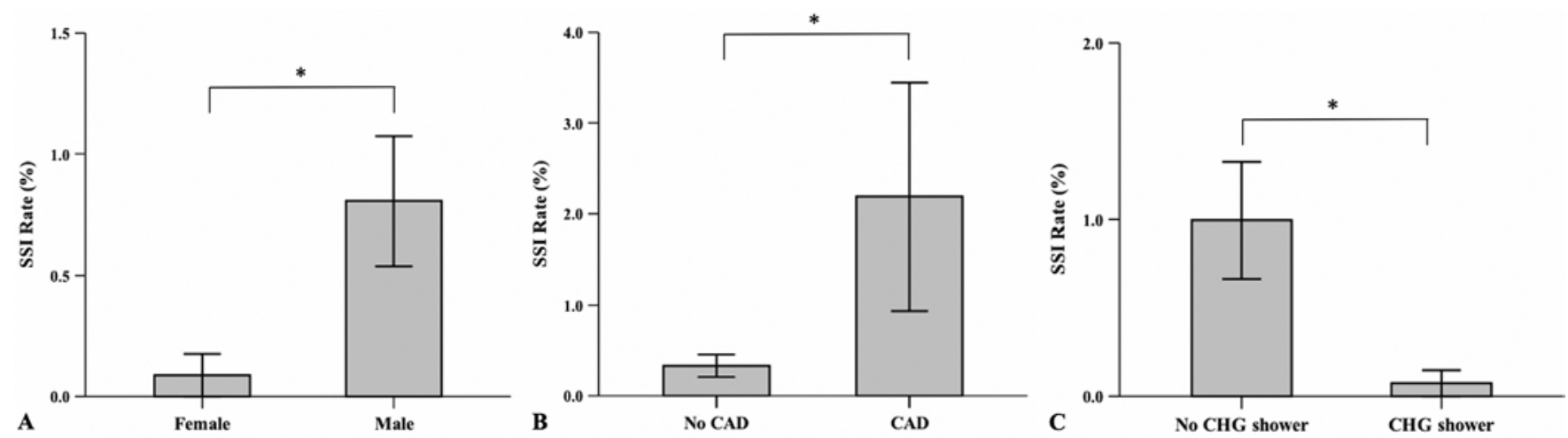

FIG. 3. Bar graphs depicting the rate of SSI in all patients who underwent thoracic or lumbar spine surgery at our institution.

A: The rate of SSI between male and female patients. B: The rate of SSI between patients with and without CAD. C: The rate of SSI between patients with and without CHG showers. ${ }^{*} p<0.05$. 
tire population of spine surgery patients at a major academic institution. This methodology adjusts for confounding variables and helps to provide insights regarding the efficacy of current standards of practice. In our retrospective cohort study of 2252 patients treated with thoracolumbar spine surgery at 1 facility, we were able to determine the absolute SSI rate as well as the rate of SSI by patient subgroup. Furthermore, we identified independent risk factors that increased SSI. Utilizing the NHSN operative procedure guidelines to identify SSI events, our overall SSI rate of $0.49 \%$ over a 4 -year time span was lower than the rates generally reported in the literature. The surveillance period for SSI was 30 days after surgery, and 90 days for fusion operations. The low rate of SSI in the present study can possibly be attributed to concerted strategies in the past decade to reduce SSI ${ }^{29,34}$ and the implementation of standardized multistep prevention measures across our institution (Fig. 1). These measures included extensive patient education and preventive strategies from before hospitalization to follow-up after surgery. In addition, there are ongoing efforts through antiseptic CHG showers to reduce the skin microflora of preoperative spine patients. ${ }^{6}$ While evidence regarding $\mathrm{CHG}$ shower is lacking in spine surgery and in other surgical specialties, ${ }^{15,26,39}$ in our spine patients presurgical CHG showering decreased SSI from $1.1 \%$ to $0.1 \%$. Given that $S$. aureus and S. epidermidis bacteria found in normal skin flora are the frequent source of SSIs, an antiseptic shower regimen may indeed decrease the infection risk of the patient at baseline relative to using unmedicated soap.

For the reasons mentioned above, the low number of SSIs over the 4-year period illustrates a strength in the evolving field of spine surgery, as well as a limitation in identifying multivariate predictors. While our study remains exploratory and in need of confirmation, nevertheless our data are important to report given the large sample size. The infection rate varied between men $(0.9 \%)$ and women $(0.1 \%)$. Reasons for this difference could be multifactorial, including variations in the propensity for skin microbial colonization and the effect of differential hormonal influence on the acute phase of wound healing. . $^{29,34}$ Few studies have reported the impact of patient sex on SSI following spine surgery. Evidence in other surgical specialties provides precedent for sex differences in SSI rates that could be procedure-specific. For example, women have lower infection rates following abdominal surgery, orthopedic procedures, and trauma than men do. ${ }^{4,8,11,17}$ In patients with central catheters, men were more likely to have bacterial colonization of the surrounding skin, and hair growth can also interfere with wound dressing and the healing process. ${ }^{8}$ Lastly, sex hormones are known to modulate inflammation and result in marked differences in the wound healing process. In particular, androgens have been associated with impaired cutaneous re-epithelialization. ${ }^{12-14,25}$

Several prior studies have explored the risk factors associated with SSI after spine surgery, ,10,24,27,31,32 which vary by institution as well as by study design. In the modern era of spine surgery, with improved perioperative medical management and preventive measures, our institutional experience suggests that smoking status and operative
TABLE 3. Subgroup analysis of patient cohorts with nonfusion and fusion surgery of the thoracic or lumbar spine

\begin{tabular}{|c|c|c|c|}
\hline Parameter & Nonfusion (\%) & Fusion (\%) & $\mathrm{p}$ Value \\
\hline No. of patients & 1084 & 1168 & \\
\hline Mean age $\pm S D$, yrs & $57.1 \pm 14.7$ & $60.1 \pm 12.7$ & $<0.001$ \\
\hline Males & $502(46.3)$ & $616(52.7)$ & 0.002 \\
\hline Mean $\mathrm{BMI} \pm \mathrm{SD}, \mathrm{kg} / \mathrm{m}^{2}$ & $28.8 \pm 6.5$ & $28.5 \pm 6.1$ & 0.299 \\
\hline $\mathrm{DM}$ & $82(7.6)$ & $96(8.2)$ & 0.585 \\
\hline CAD & $59(5.4)$ & $79(6.8)$ & 0.218 \\
\hline History of malignancy & $96(8.9)$ & $119(10.2)$ & 0.350 \\
\hline Smoker & $111(10.2)$ & $131(11.2)$ & 0.451 \\
\hline Ambulation & $892(82.3)$ & $945(80.9)$ & 0.399 \\
\hline CHG shower & $625(57.7)$ & $722(61.8)$ & 0.044 \\
\hline ASA classification & & & $<0.001$ \\
\hline$\leq \|$ & $694(64.0)$ & $607(52.0)$ & \\
\hline$>$ II & $390(36.0)$ & $561(48.0)$ & \\
\hline Surgical pathology & & & 0.301 \\
\hline Degenerative & $683(63.0)$ & $711(60.9)$ & \\
\hline Deformity & $136(12.5)$ & $167(14.3)$ & \\
\hline Tumor & $173(16.0)$ & $206(17.6)$ & \\
\hline Trauma & $27(2.5)$ & $19(1.6)$ & \\
\hline Other & $65(6.0)$ & $65(5.6)$ & \\
\hline Resident involvement & $849(78.3)$ & $904(77.4)$ & 0.598 \\
\hline Open vs MIS surgery & & & 0.021 \\
\hline Open & $826(76.2)$ & $937(80.2)$ & \\
\hline MIS & $258(23.8)$ & $231(19.8)$ & \\
\hline Revision & $137(12.6)$ & $146(12.5)$ & 0.921 \\
\hline Surgical level & & & 0.768 \\
\hline $\begin{array}{l}\leq 5 \text {-level thoracic/thoraco- } \\
\text { lumbar }\end{array}$ & $108(10.0)$ & $128(11.0)$ & \\
\hline$\leq \mathrm{L} 2-\mathrm{S} 1$ & $871(80.4)$ & $918(78.6)$ & \\
\hline$>$ L2-S1 \& < T10-pelvis & $82(7.6)$ & $97(8.3)$ & \\
\hline$\geq \mathrm{T} 10$-pelvis & $23(2.1)$ & $25(2.1)$ & \\
\hline Surgical approach & & & $<0.001$ \\
\hline Posterior & $1084(100)$ & $625(53.5)$ & \\
\hline Anterior & $0(0)$ & $324(27.8)$ & \\
\hline Lateral & $0(0)$ & $78(6.7)$ & \\
\hline 2-stage & $0(0)$ & $141(12.1)$ & \\
\hline Intraop antibiotics & $1035(95.5)$ & $1121(96.0)$ & 0.560 \\
\hline Postop antibiotics & $710(65.5)$ & $783(67.0)$ & 0.440 \\
\hline Pre/postop steroids & $459(42.3)$ & $525(45.0)$ & 0.206 \\
\hline EBL, L & & & 0.071 \\
\hline$<1$ & $900(87.3)$ & $955(84.6)$ & \\
\hline$\geq 1$ & $131(12.7)$ & $174(15.4)$ & \\
\hline Op duration, hrs & & & $<0.001$ \\
\hline$<2$ & $328(30.3)$ & $93(8.0)$ & \\
\hline $2-5$ & $592(54.6)$ & $760(65.1)$ & \\
\hline$>5$ & $164(15.1)$ & $314(26.9)$ & \\
\hline Mean $L O S \pm S D$, days & $6.6 \pm 7.7$ & $6.6 \pm 7.1$ & 0.937 \\
\hline
\end{tabular}

Boldface type indicates statistical significance. 

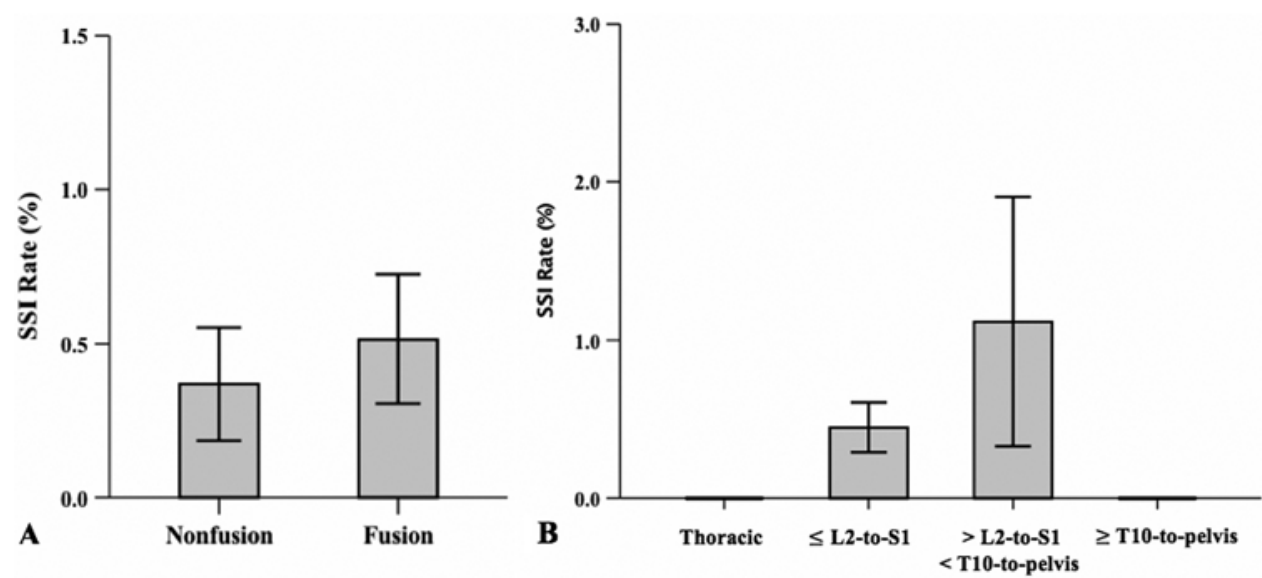

FIG. 4. Bar graphs depicting the rate of SSI in patients according to the type of surgery. A: The rate of SSI between fusion and nonfusion patients. B: The rate of SSI by spinal location.

time are not risk factors for increased infection. However, in addition to DM affecting postoperative healing, we found that CAD is associated with increased odds of SSI following thoracolumbar spine surgery. Patients with CAD $(2.9 \%)$ had a higher infection rate than those without the comorbidity (0.3\%). CAD can be an infection risk for several reasons. It has been associated with prolonged recovery, which predisposes the patient to greater risks of postoperative complications. ${ }^{3}$ Patients with cardiac disease may be prone to experience anemia with surgical blood loss, ${ }_{16,22}$ and understanding the link between postsurgical transfusion and SSI is a topic of interest in future investigations. Despite prophylactic antibiotic administration, these patients may be at risk for decreased delivery of antibiotics in addition to hypoperfusion and poor blood supply of the surgical wound secondary to general vasculopathy. ${ }^{14}$

We found that patients with diabetes experienced a higher rate of SSI (1.7\%) than those without diabetes $\left(0.4 \%\right.$, comparable to previous publications $\left.{ }^{2,10,24,27}\right)$. For our patients, the target for presurgery hemoglobin A1C score was less than $7.5 \%$, with the exception of operations that could not be delayed. Fusion was not associated with increased rate of SSIs and prolonged LOS in this study, which can vary with discharge practices and patient pathology. Patients with tumor or deformity pathologies make up a small sample relative to degenerative diseases, with wide variability in management in these patients. Pathology-specific risk factors are in need of validation through larger patient populations. Of the 11 infection cases, 4 patients had a history of steroid use and 1 with immunosuppressant medication use, which may be a risk factor for increased infection. Patients with postoperative antibiotics for drain prophylaxis had a lower rate of SSI $(0.3 \%)$ than patients without $(0.8 \%)$, but this difference was not statistically significant. Larger studies-without compromising data granularity-can help clarify the effect of postoperative drain prophylaxis. This suggests that male sex and CAD may be more important predictors of SSI in the thoracic or lumbar spinal procedure population. Of note, at our center, we ask patients undergoing spine surgery to quit smoking perioperatively.

\section{Limitations and Strengths}

The limitations of our findings arise from the retrospective nature of our study. The rate of SSI was quite low in our study. While conferring the benefits of modern surgical technique and infection control protocols, such as those at our institution (Figs. 1 and 2), this low number of SSIs also limits statistical power and the identification of validated multivariable predictors, which await the results of larger studies on the topic. Our reported rate of SSI following spine surgery was also lower than prior reports. Reasons for this include differences in patient population, spinal pathology, and institutional practices. ${ }^{38}$ SSIs occurring outside of the surveillance window per the NHSN guidelines were not included in our study. Gradual changes to surgical practice patterns and patient populations over time can limit the generalizability of the results reported herein. Of interest for future investigations are other variables that could influence the wound healing process, such as chronic immunosuppressant drug use and preoperative nutritional status of the patient. Patients who received surgeries starting in November 2013 were provided detailed instructions and CHG liquid soap in preparation for surgery. While we did not quantify the rate of patient adherence, CHG shower decreased SSI following implementation of the protocol, as described in our prior publication. ${ }^{6}$ The strengths of the current study were the degree of detail and completeness of clinical information obtained for every patient to help assess the magnitude of risk that was associated with each factor.

\section{Conclusions}

In a cohort of 2252 consecutive patients undergoing surgery for thoracolumbar spine disorders at our institution, the rate of SSI according to the NHSN criteria was low at $0.49 \%$ and attributable to the use of standardized patient optimization and education from before surgery to follow-up after discharge from the hospital, as well as due to implementation of an antisepsis preoperative CHG showering protocol across our institution. We found that being male and having a history of CAD were risk factors 
for increased SSI in addition to DM, whereas preoperative CHG shower utilization decreased SSI. Furthermore, obesity and smoking history were not associated with infections in our patient population, likely from preoperative optimization. Prospective studies are needed to further investigate causal factors of SSI, and to evaluate strategies for infection reduction in this cohort of at-risk patients.

\section{References}

1. Abbey DM, Turner DM, Warson JS, Wirt TC, Scalley RD: Treatment of postoperative wound infections following spinal fusion with instrumentation. J Spinal Disord 8:278-283, 1995

2. Abdul-Jabbar A, Takemoto S, Weber MH, Hu SS, Mummaneni PV, Deviren V, et al: Surgical site infection in spinal surgery: description of surgical and patient-based risk factors for postoperative infection using administrative claims data. Spine (Phila Pa 1976) 37:1340-1345, 2012

3. Bekelis K, Desai A, Bakhoum SF, Missios S: A predictive model of complications after spine surgery: the National Surgical Quality Improvement Program (NSQIP) 2005-2010. Spine J 14:1247-1255, 2014

4. Brandt C, Sohr D, Behnke M, Daschner F, Rüden H, Gastmeier P: Reduction of surgical site infection rates associated with active surveillance. Infect Control Hosp Epidemiol 27:1347-1351, 2006

5. Calderone RR, Garland DE, Capen DA, Oster H: Cost of medical care for postoperative spinal infections. Orthop Clin North Am 27:171-182, 1996

6. Chan AK, Ammanuel SG, Chan AY, Oh T, Skrehot HC, Edwards CS, et al: Chlorhexidine showers are associated with a reduction in surgical site infection following spine surgery: an analysis of 4266 consecutive surgeries. Neurosurgery [epub ahead of print], 2018

7. Chen S, Anderson MV, Cheng WK, Wongworawat MD: Diabetes associated with increased surgical site infections in spinal arthrodesis. Clin Orthop Relat Res 467:1670-1673, 2009

8. Cohen B, Choi YJ, Hyman S, Furuya EY, Neidell M, Larson $\mathrm{E}$ : Gender differences in risk of bloodstream and surgical site infections. J Gen Intern Med 28:1318-1325, 2013

9. Deng H, Yue JK, Ordaz A, Rivera EJ, Suen CG, Sing DC: Cervical fusion for degenerative disease: a comprehensive cost analysis of hospital complications in the United States from 2002 to 2014. J Craniovertebr Junction Spine 9:140147, 2018

10. Fang A, Hu SS, Endres N, Bradford DS: Risk factors for infection after spinal surgery. Spine (Phila Pa 1976) 30:14601465,2005

11. Gibbons C, Bruce J, Carpenter J, Wilson AP, Wilson J, Pearson A, et al: Identification of risk factors by systematic review and development of risk-adjusted models for surgical site infection. Health Technol Assess 15:1-156, iii-iv, 2011

12. Gilliver SC, Ashworth JJ, Ashcroft GS: The hormonal regulation of cutaneous wound healing. Clin Dermatol 25:56-62, 2007

13. Grossman CJ: Interactions between the gonadal steroids and the immune system. Science 227:257-261, 1985

14. Guo S, Dipietro LA: Factors affecting wound healing. J Dent Res 89:219-229, 2010

15. Hayek L: A placebo-controlled trial of the effect of two preoperative baths or showers with chlorhexidine detergent on postoperative wound infection rates. J Hosp Infect 13:202204, 1989

16. Hollis RH, Singletary BA, McMurtrie JT, Graham LA, Richman JS, Holcomb CN, et al: Blood transfusion and 30-day mortality in patients with coronary artery disease and anemia following noncardiac surgery. JAMA Surg 151:139-145, 2016

17. Langelotz C, Mueller-Rau C, Terziyski S, Rau B, Krannich A, Gastmeier P, et al: Gender-specific differences in surgical site infections: an analysis of 438,050 surgical procedures from the German National Nosocomial Infections Surveillance System. Viszeralmedizin 30:114-117, 2014

18. Levi AD, Dickman CA, Sonntag VK: Management of postoperative infections after spinal instrumentation. J Neurosurg 86:975-980, 1997

19. Liu CY, Zygourakis CC, Yoon S, Kliot T, Moriates C, Ratliff $\mathrm{J}$, et al: Trends in utilization and cost of cervical spine surgery using the National Inpatient Sample Database, 2001 to 2013. Spine (Phila Pa 1976) 42:E906-E913, 2017

20. Malis LI: Prevention of neurosurgical infection by intraoperative antibiotics. Neurosurgery 5:339-343, 1979

21. McGirt MJ, Parker SL, Lerner J, Engelhart L, Knight T, Wang MY: Comparative analysis of perioperative surgical site infection after minimally invasive versus open posterior/ transforaminal lumbar interbody fusion: analysis of hospital billing and discharge data from 5170 patients. J Neurosurg Spine 14:771-778, 2011

22. Nappi J: Anemia in patients with coronary artery disease. Am J Health Syst Pharm 60 (14 Suppl 3):S4-S8, 2003

23. Olsen MA, Mayfield J, Lauryssen C, Polish LB, Jones M, Vest J, et al: Risk factors for surgical site infection in spinal surgery. J Neurosurg 98 (2 Suppl):149-155, 2003

24. Olsen MA, Nepple JJ, Riew KD, Lenke LG, Bridwell KH, Mayfield J, et al: Risk factors for surgical site infection following orthopaedic spinal operations. J Bone Joint Surg Am 90:62-69, 2008

25. Pergola C, Rogge A, Dodt G, Northoff H, Weinigel C, Barz $\mathrm{D}$, et al: Testosterone suppresses phospholipase $\mathrm{D}$, causing sex differences in leukotriene biosynthesis in human monocytes. FASEB J 25:3377-3387, 2011

26. Prabhu AS, Krpata DM, Phillips S, Huang LC, Haskins IN, Rosenblatt S, et al: Preoperative chlorhexidine gluconate use can increase risk for surgical site infections after ventral hernia repair. J Am Coll Surg 224:334-340, 2017

27. Pull ter Gunne AF, Cohen DB: Incidence, prevalence, and analysis of risk factors for surgical site infection following adult spinal surgery. Spine (Phila Pa 1976) 34:1422-1428, 2009

28. Rechtine GR, Bono PL, Cahill D, Bolesta MJ, Chrin AM: Postoperative wound infection after instrumentation of thoracic and lumbar fractures. J Orthop Trauma 15:566-569, 2001

29. Shaffer WO, Baisden JL, Fernand R, Matz PG: An evidencebased clinical guideline for antibiotic prophylaxis in spine surgery. Spine J 13:1387-1392, 2013

30. Smith JS, Shaffrey CI, Sansur CA, Berven SH, Fu K-MG, Broadstone PA, et al: Rates of infection after spine surgery based on 108,419 procedures: a report from the Scoliosis Research Society Morbidity and Mortality Committee. Spine (Phila Pa 1976) 36:556-563, 2011

31. Tominaga H, Setoguchi T, Kawamura H, Kawamura I, Nagano S, Abematsu M, et al: Risk factors for unavoidable removal of instrumentation after surgical site infection of spine surgery: a retrospective case-control study. Medicine (Baltimore) 95:e5118, 2016

32. Tsubouchi N, Fujibayashi S, Otsuki B, Izeki M, Kimura H, Ota M, et al: Risk factors for implant removal after spinal surgical site infection. Eur Spine J 27:2481-2490, 2018

33. von Elm E, Altman DG, Egger M, Pocock SJ, Gøtzsche PC, Vandenbroucke JP: The Strengthening the Reporting of Observational Studies in Epidemiology (STROBE) Statement: guidelines for reporting observational studies. Int J Surg 12:1495-1499, 2014

34. Watters WC III, Baisden J, Bono CM, Heggeness MH, Res- 
nick DK, Shaffer WO, et al: Antibiotic prophylaxis in spine surgery: an evidence-based clinical guideline for the use of prophylactic antibiotics in spine surgery. Spine J 9:142-146, 2009

35. Whitmore RG, Stephen J, Stein SC, Campbell PG, Yadla S, Harrop JS, et al: Patient comorbidities and complications after spinal surgery: a societal-based cost analysis. Spine (Phila Pa 1976) 37:1065-1071, 2012

36. Wimmer C, Gluch H, Franzreb M, Ogon M: Predisposing factors for infection in spine surgery: a survey of 850 spinal procedures. J Spinal Disord 11:124-128, 1998

37. Young RF, Lawner PM: Perioperative antibiotic prophylaxis for prevention of postoperative neurosurgical infections. A randomized clinical trial. J Neurosurg 66:701-705, 1987

38. Zygourakis CC, Liu CY, Keefe M, Moriates C, Ratliff J, Dudley RA, et al: Analysis of national rates, cost, and sources of cost variation in adult spinal deformity. Neurosurgery 82:378-387, 2018

39. Zywiel MG, Daley JA, Delanois RE, Naziri Q, Johnson AJ, Mont MA: Advance pre-operative chlorhexidine reduces the incidence of surgical site infections in knee arthroplasty. Int Orthop 35:1001-1006, 2011

\section{Disclosures}

Dr. A. K. Chan reports support of non-study-related clinical or research effort from Orthofix. Dr. Dhall reports being a consultant to DePuy Synthes. Dr. Clark reports being a consultant to NuVasive. Dr. Chou reports being a consultant to Medtronic and Globus, and receiving a small royalty from Globus. Dr.

Ames reports being a consultant to DePuy Synthes, Medtronic, Stryker, Medicrea, K2M, and Biomet Zimmer; receiving royalties from Stryker, Biomet Zimmer, DePuy Synthes, NuVasive, Next Orthosurgical, K2M, and Medicrea; conducting research for Titan Spine, DePuy Synthes, and ISSG; being on the editorial board of Operative Neurosurgery; receiving grant funding from SRS; being on the Executive Committee of ISSG; and being the director of Global Spine Analytics. Dr. Mummaneni reports being a consultant to DePuy Spine, Globus, and Stryker; direct stock ownership in Spinicity/ISD; receiving statistical analysis for study/writing or editorial assistance on the manuscript from ISSG; receiving support of non-study-related clinical or research effort from the NREF; receiving royalties from DePuy Spine, Thieme Publishing, and Springer Publishing; and receiving honoraria from Spineart.

\section{Author Contributions}

Conception and design: Deng, AK Chan, Oh, Liu, Yue, Dhall, Clark, Chou, Ames, Mummaneni. Acquisition of data: AK Chan, Ammanuel, AY Chan, Skrehot, Edwards, Kondapavulur, Nichols, Liu, Dhall, Clark, Chou, Ames, Mummaneni. Analysis and interpretation of data: Deng, AK Chan, Ammanuel, AY Chan, Skrehot, Kondapavulur, Nichols, Yue. Drafting the article: Deng, AK Chan, Edwards, Nichols, Yue, Chou, Mummaneni. Critically revising the article: all authors. Reviewed submitted version of manuscript: all authors. Approved the final version of the manuscript on behalf of all authors: Deng. Statistical analysis: Deng, Liu. Administrative/technical/material support: Ammanuel, AY Chan, Skrehot, Edwards, Kondapavulur, Nichols, Liu, Mummaneni. Study supervision: AK Chan, Oh, Yue, Dhall, Clark, Chou, Ames, Mummaneni.

\section{Supplemental Information Online-Only Content}

Supplemental material is available with the online version of the article.

Supplemental Fig. 1 and Supplemental Tables 1 and 2. https://thejns.org/doi/suppl/10.3171/2019.8.SPINE19479.

\section{Correspondence}

Hansen Deng: University of Pittsburgh Medical Center, Pittsburgh, PA.hdneurosurg@gmail.com. 